\title{
Hand hygiene knowledge and practices among healthcare providers in a tertiary hospital, South West Nigeria
}

\author{
'Timothy A Ekwere, ${ }^{2}$ Ifeoma P Okafor
}

1. Department of Haematology, College of Health Sciences, University of Uyo, Uyo, Akwa Ibom State, Nigeria

2. Department of Community Health \& Primary Care, College of Medicine, University of Lagos, Lagos, Nigeria

doi: 10.3396/IJIC.v9i4.032.13

\begin{abstract}
Proper hand hygiene is an important means of preventing nosocomial infections. This study aimed to assess knowledge, attitude and hand hygiene practices among healthcare providers (HCPs) in Lagos University Teaching Hospital (LUTH), Lagos, South-West Nigeria.

A cross-sectional study was conducted in August 2011. Simple random sampling was used to select $500 \mathrm{HCPs}$ (250 doctors and 250 nurses). Data collection was done with self-administered structured questionnaires. Data obtained were analyzed with SPSS version 11.5.

A total of $430 \mathrm{HCPs}$ (230 doctors and 200 nurses) participated in this study giving a response rate of $86 \%$. Eighty-three percent had good knowledge; $97.6 \%$ had good attitude and $69.9 \%$ had good hand washing practices. Hand washing after contact with patient (97.7\%) was better than before contact (61.4\%). Nurses had better hand washing practices than doctors (Fisher's exact $p<0.001$ ) and were more likely to wash their hands before patient contact than doctors $(p<0.001)$. Training on infection control had a significant positive influence on HCPs knowledge and hand washing practices (Fisher's exact $p<0.001$ and Fisher's exact $p<0.001$ respectively). The commonly used hand-drying methods were personal handkerchief $(28.8 \%)$, common cloth towel $(22.6 \%)$ and natural air drying (29.5\%). The major motivation for hand washing was fear of contracting disease while the major constraint was busy work schedule in-between patient care.

HCPs in LUTH have good hand washing knowledge but suboptimal practices especially with hand-drying. Hospital management should provide proper hand drying facilities, reduce work load and organize training on infection control on a regular basis.
\end{abstract}

Keywords: Hand hygiene; Cross infection and prevention and control; Health personnel; Nigeria

\section{Corresponding author}

Timothy A Ekwere

Address: Department of Haematology, College of Health Sciences, University of Uyo, Uyo, Akwa Ibom State.

Email: timothyekwere@yahoo.com 


\section{Introduction}

Most healthcare-associated infections (HAI) are thought to be transmitted by the hands of Healthcare Providers (HCPs) through direct contact, mainly when the hands of HCPs transfer microorganisms between individuals or between individuals and the environmental reservoir. ${ }^{1}$ It has long been known that hand hygiene among HCPs plays a central role in preventing the transmission of infectious agents.

Despite the relative simplicity of this procedure, adherence to hand washing recommendations is unacceptably low, usually well below $50 \% .^{2-4}$ Some of the reasons for lack of adherence or compliance to hand-washing include; lack of appropriate equipment, low staff to patient ratios, allergies to hand washing products, insufficient knowledge among HCPs about risk and procedures, the time required and casual attitudes among HCPs towards biosafety. ${ }^{5}$ The impact of HAl include prolonged hospital stay, long term disability and increased resistance of micro-organisms to antimicrobials, massive additional financial burden on the patients and families and in some cases, death. ${ }^{4}$

In developed countries, HAI affects about $5-15 \%$ of hospitalized patients. ${ }^{6}$ The rate is higher among those in intensive care units (ICUs), between 9-37\%.6.7 The incriminating organisms are often microbial isolates of resistant organisms. ${ }^{8}$ Hospitals in Europe Link for Infection Control through Surveillance (HELICS) estimates millions of extra days of hospital stay and huge economic burden. ${ }^{9,10}$ In the United States of America (USA), the estimated HAI incidence rate in the year 2004 was $4.5 \%$ with a fatality rate of $5 \%$ and a huge economic impact. ${ }^{11,12}$ Poor hand hygiene among healthcare workers was identified as one of the major causes of the infections.

While nosocomial infection surveillance is already a challenging task in developed countries, paucity of data and other factors add to this challenge. ${ }^{13}$ This makes it imperative to prevent these infections.

The magnitude of this problem is particularly relevant in our environment where basic infection control measures are usually lacking or non-existent in most health facilities. This is the result of a combination of factors such as understaffing, poor hygiene and sanitation, lack or shortage of basic equipment and inadequate structures and overcrowding, all of which may be attributed to limited financial resources. ${ }^{10}$ Under these conditions, numerous infections are still acquired from both patients and HCPs through poor hand hygiene, unsafe use of injections, medical devices and blood products, inadequate surgical procedures and deficiencies in medical waste disposal..$^{13}$ In addition to these factors, an unfavourable social background and population largely affected by malnutrition and other types of infection and/or disease contribute to the increased risk of $\mathrm{HAI}$ in developing countries. ${ }^{13,14}$

Prevalence studies of nosocomial infection in developing countries have reported higher rates than developed countries. ${ }^{15-17}$ Improved compliance with hand washing has been shown to be associated with significant decrease in overall rates of $\mathrm{HAI}$ and respiratory infections in particular. ${ }^{18}$ Therefore hand washing is recommended before and after every patient contact to break the chain of infection.

The objectives of this study were thus; to assess the knowledge, attitude and practice of this simple intervention "hand-washing", identify the hand-drying methods commonly used by the HCPs and also identify factors that motivate and militate against hand washing practices amongst HCPs at the Lagos University Teaching Hospital (LUTH), a tertiary hospital in Lagos, Nigeria. The information generated from this study will identify gaps, if any, in health providers' hand hygiene. It will assist the hospital management and the infection control unit of the hospital to put in place appropriate measures for successful implementations of its hand washing policy.

\section{Methodology}

The study was conducted at the Lagos University Teaching Hospital (LUTH). It is a foremost tertiary referral centre providing patient care to residents of Lagos and neighbouring states. The hospital has 761 bed spaces and 25 in-patient wards, including the Intensive Care Unit (ICU). There were 654 doctors and 734 nurses at the time of study. Hand-washing facilities are located in all the wards and clinics in the hospitals. Each ward/clinic is provided with at least a wash hand shank, running tap water, soap (liquid or bar) and sometimes, a cloth towel for hand drying. 
Stored water in plastic drums and buckets are provided as alternative source of water supply when there is lack of running tap water, usually caused by irregular power supply.

There is an infection control committee in the hospital which is chaired by the Head of Medical Microbiology and Parasitology Department. This committee periodically organizes seminars and training on various aspects of infection control, including handwashing, to the hospital community especially newly recruited medical and paramedical staff. Prior to the study, several of such seminars had been conducted for various cadres of staff in the hospital. In addition, individual departments also conduct seminars on infection control for their staff.

\section{Study Design}

This was a cross-sectional descriptive study, designed to assess the knowledge, attitude and practice of hand washing including hand-drying methods as well as identify factors that motivate and/or militate against hand washing practices by doctors and nurses in LUTH.

\section{Study population}

The study populations were healthcare providers working in LUTH. Only doctors and nurses who were working in the various wards in the hospital at the time of study and had served for a minimum of one year with the hospital, were included in the study. Doctors and nurses who were not working on the wards at the time of the study and those who had worked for less than one year were excluded. Other medical and nonmedical personnel were also excluded.

\section{Sampling method}

A minimum sample size was calculated using the formula for descriptive studies. However the figure was increased to 500, also taking into account a nonresponse rate of $20 \%$. An equal proportion of doctors and nurses were recruited. Lists of all the doctors and nurses who were on duty in the wards in the month of study were obtained and served as sampling frame. By simple random sampling, using computer generated random numbers, $20 \mathrm{HCPs}$ (10 nurses and 10 doctors) were selected in each ward making a total of 500 .

\section{Data Collection}

Data collection was done in August 2011, using a pretested, structured, self administered questionnaire. The questionnaires were delivered to the respondents in the ward and were collected soon after. They were provided with envelopes and instructed to drop them at a designated collection point in the ward. Some of them however, failed to return theirs.

\section{Data analysis}

Data was analyzed using SPSS for windows Version 11.5. and Microsoft Excel. Descriptive statistics and inferential statistics using Chi Square $\left(X^{2}\right)$ and student t-test were used as appropriate. The level of significance was set at $5 \%(p<0.05)$.

Knowledge and practice were scored in percentages and graded. A score of $0-33.3 \%$ was considered poor, $>33.3-\leq 66.6 \%$ was fair and $>66.6 \%$ was good. Attitude was assessed with Likert items. Each Likert item was rated on a 1-5 response scale; where strongly agree $=5$, agree-4, neutral=3, disagree $=2$, strongly disagree $=1$. The scores were graded into positive, neutral or negative.

\section{Ethics}

Ethical approval was obtained from the Ethics and Research Committee of the hospital. Formal consent was obtained from the respondents prior to administration of questionnaire.

\section{Results}

Of the 500 questionnaires distributed, 430 questionnaires were adequately filled and returned. This gives a response rate of $86.0 \%$, out of which 230 $(53.5 \%)$ were from doctors and $200(46.5 \%)$ were from nurses. There were $162(37.7 \%)$ males and $268(62.3 \%)$ females. Their mean age was $31.3 \pm 6.8$ years. Majority, (84.9\%) of the respondents had spent between 1 to 10 years in service (Table I). The awareness of respondents on the availability of infection control unit and hospital policy on hand washing in the institution was $74.7 \%$ and $69.5 \%$ respectively. Two hundred and forty three (56.5\%) respondents had attended training or seminar on infection control with respect to hand washing. The major source of information on the existence of hospital policy on hand washing and infection control unit was from the hospital seminar (44.0\%). 


\begin{tabular}{|c|c|}
\hline Variables & Frequency $(\%)(n=430)$ \\
\hline \multicolumn{2}{|l|}{ Age (Years) } \\
\hline $15-24$ & $77(17.9)$ \\
\hline $25-34$ & $223(51.9)$ \\
\hline $35-44$ & $110(25.6)$ \\
\hline $45-54$ & $20(4.6)$ \\
\hline \multicolumn{2}{|l|}{ Sex } \\
\hline Male & $162(37.7)$ \\
\hline Female & $268(62.3)$ \\
\hline \multicolumn{2}{|c|}{ Marital Status } \\
\hline Single & $207(48.2)$ \\
\hline Married & $222(51.6)$ \\
\hline Others & $1(0.2)$ \\
\hline \multicolumn{2}{|l|}{ Religion } \\
\hline Christianity & $346(80.5)$ \\
\hline Islam & $84(19.5)$ \\
\hline \multicolumn{2}{|c|}{ Years of Service } \\
\hline $1-10$ & $365(4.9)$ \\
\hline $11-20$ & $52(12.5)$ \\
\hline$\geq 20$ & $13(3.0)$ \\
\hline \multicolumn{2}{|l|}{ Profession } \\
\hline Nurse & $200(46.5)$ \\
\hline Doctor & $230(53.5)$ \\
\hline
\end{tabular}

Majority, (91.2\%) of respondents had good knowledge of the components of a good hand washing technique and almost all (98.8\%) of the respondents knew that contaminated hands can serve as a vehicle for the transmission of infection from one patient to another. Sixty-seven percent also knew that effective hand washing involves washing of hands for a period not less than 30 seconds.

Almost $94 \%$ of respondents knew that nosocomial infections have a high impact on patients' clinical outcome. A similar proportion of respondents (96\%) knew that effective hand washing is highly effective in preventing the transmission of $\mathrm{HAl}$ from one patient to another. Overall, the majority of respondents $(83.0 \%)$ had good knowledge of hand hygiene (Table II).

Seventy-seven percent of the respondents strongly agreed that hand washing is protective to them. The major motivation to hand washing by the respondents was fear of contracting disease $(87.90 \%)$, while the major constraint was the busy work schedule of respondents in between patient care (56.5\%). Almost all HCPs (97.5\%) believed that administrative order and continuous health education can improve hand washing among them. Overall, almost all respondents (96.75\%) had a positive attitude to hand washing, with only $3.3 \%$ of them being indifferent (Table III).

Regarding their practices, $97.7 \%$ of respondents wash their hands more often after contact or bed side procedure than before (61.4\%). A majority, $(82.5 \%)$ of respondents dry their hands after washing. Also a large proportion of respondents (77.0\%) wash their hands after the close of the day's work. Running tap water with antiseptic soap were most commonly used for hand washing $(68.4 \%)$. Allowing their hands to air dry $(29.5 \%)$ was the most commonly used hand drying technique, followed by the use of personal handkerchief $(28.8 \%)$ and common cloth towel $(22.6 \%)$. For $299(69.5 \%)$ of the respondents, their practices with regards to hand washing was good, for $124(28.8 \%)$ it was fair, while for $7(1.6 \%)$ it was poor (Table IV).

Doctors had a non-significant better knowledge 192 $(83.5 \%)$ of hand washing than nurses $165(82.5 \%)$ $(p=0.051)$. None of the doctors had poor knowledge unlike $5 \%$ of the nurses. There was a statistically significant association between attending a training or seminar on infection control and knowledge of hand washing (Fisher's exact $\mathrm{p}<0.001$ ). Respondents who attended training/seminar on infection control and hand washing had significantly better hand washing practices $(78.6 \%)$ than those who did not attend such training $(57.8 \%)$ (Table V).

Before contact or bedside procedure with patients, nurses had significantly better hand washing practices (78\%) than doctors (47\%). Doctors had significantly better practice of hand washing after contact or bedside procedure $(p=0.014)$. Overall, Nurses had significantly better hand washing practices than doctors $(p=0.013)$ (Table VI).

\section{Discussion}

Hand hygiene is known to prevent cross infection in hospitals, however adherence to its guidelines is 


\section{Table II. Respondents' knowledge on hand hygiene}

Variables $(\mathrm{n}=430)$

Frequency $(\%)$

Components of hand washing

Use of soapy water in basin

Use of running tap water only

Use of running water and antiseptic soap

Use of alcohol only

I don't know

\section{Multiple responses}

\section{Contaminated hands is a vehicle for transmitting infection}

Yes

No

\section{Effective hand washing should last for at least $\mathbf{3 0}$ seconds}

Yes

No

I don't know

$86(20)$

\section{Impact of Nosocomial infection on patient clinical outcome}

Very high

High

Low

Very low

I don't know

\section{Effectiveness of hand washing in preventing Nosocomial infection}

Very high

High

Low

I don't know

\section{Overall Knowledge}

Poor

Fair

Good

rather poor. ${ }^{19}$ This study has revealed that HCPs at the Lagos University Teaching Hospital have good knowledge of hand washing $(83 \%)$. This finding is similar to that reported among healthcare staff in ICU of a Multispecialty hospital in India (90\%), but higher than figures reported among HCPs in Cairo in Elgalea Government Hospital (73.1\%), and Cleopatra Private Hospital $(72.7 \%)^{20,21}$ It is also much better than the findings at the University of Port Harcourt Teaching Hospital (UPTH) in which more than half of the HCPs $(55.4 \%)$ lack good knowledge of hand washing. ${ }^{22}$ The high level of knowledge on hand washing by the respondents is not unexpected by virtue of their medical background. Also, working in a tertiary centre provides them a lot of opportunities to attend various seminars and training on infection control. More than $50 \%$ of the respondents in this study have attended such training/seminars and they had a significantly better knowledge of hand washing than their counterparts who did not.

A positive attitude towards hand washing was also demonstrated in this study $(96.7 \%)$. Similar findings have been reported in other studies. ${ }^{21,23}$ In Cairo, nurses were also found to have a positive attitude $(96.0 \%) .{ }^{21}$ Same was reported among HCPs in intensive care unit (ICU) in Italy $(86.2 \%) .{ }^{23}$ This positive attitude towards hand washing exhibited by the respondents may be 
Table III.Attitude of respondents towards hand washing

\begin{tabular}{|c|c|c|c|c|c|c|}
\hline & $\begin{array}{r}\text { Strongly } \\
\text { agree }\end{array}$ & Agree & Indifferent & Disagree & $\begin{array}{l}\text { Strongly } \\
\text { Disagree }\end{array}$ & Total \\
\hline $\begin{array}{l}\text { Hand washing can be } \\
\text { protective to HCWs }\end{array}$ & $\begin{array}{r}331 \\
(77.0 \%) \\
\end{array}$ & $\begin{array}{r}96 \\
(22.3 \%) \\
\end{array}$ & $3(0.7 \%)$ & $0(.0 \%)$ & $0(0.0 \%)$ & $\begin{array}{r}430 \\
(100.0 \%) \\
\end{array}$ \\
\hline $\begin{array}{l}\text { Hand washing should be done } \\
\text { when in contact with all patients } \\
\text { and patient's formites. }\end{array}$ & $\begin{array}{r}270 \\
(62.8 \%)\end{array}$ & $\begin{array}{r}135 \\
(31.4 \%)\end{array}$ & $\begin{array}{r}7 \\
(1.6 \%)\end{array}$ & $\begin{array}{r}17 \\
(4.0 \%)\end{array}$ & $\begin{array}{r}1 \\
(0.2 \%)\end{array}$ & $\begin{array}{r}430 \\
(100.0 \%)\end{array}$ \\
\hline $\begin{array}{l}\text { Hand washing is often not } \\
\text { adhered to because of busy work } \\
\text { schedule in between patients. }\end{array}$ & $\begin{array}{r}80 \\
(18.6 \%)\end{array}$ & $\begin{array}{r}163 \\
(37.9 \%)\end{array}$ & $\begin{array}{r}53 \\
(12.3 \%)\end{array}$ & $\begin{array}{r}102 \\
(23.7 \%)\end{array}$ & $\begin{array}{r}32 \\
(7.5 \%)\end{array}$ & $\begin{array}{r}430 \\
(100.0 \%)\end{array}$ \\
\hline $\begin{array}{l}\text { HCWs are motivated to wash } \\
\text { their hands because of fear of } \\
\text { contracting disease }\end{array}$ & $\begin{array}{r}174 \\
(40.5 \%)\end{array}$ & $\begin{array}{r}204 \\
(47.4 \%)\end{array}$ & $\begin{array}{r}28 \\
(6.5 \%)\end{array}$ & $\begin{array}{r}17 \\
(4.0 \%)\end{array}$ & $\begin{array}{r}7 \\
(1.6 \%)\end{array}$ & $\begin{array}{r}430 \\
(100.0 \%)\end{array}$ \\
\hline $\begin{array}{l}\text { Hand washing can be improved } \\
\text { by administrative order and } \\
\text { continuous health education }\end{array}$ & $\begin{array}{r}236 \\
(54.9 \%)\end{array}$ & $\begin{array}{r}183 \\
(42.6 \%)\end{array}$ & $\begin{array}{r}4 \\
(0.9 \%)\end{array}$ & $\begin{array}{r}5 \\
(1.2 \%)\end{array}$ & $\begin{array}{r}2 \\
(0.4 \%)\end{array}$ & $\begin{array}{r}430 \\
(100.0 \%)\end{array}$ \\
\hline
\end{tabular}

\section{Overall Attitude}

Frequency (\%)

Positive $416(96.7)$

Indifferent

$14(3.3)$

Total

attributed to their knowledge of the consequences of poor hand hygiene.

Many studies on the practice of hand washing by HCPs have reported low compliance rate. ${ }^{3,21,24}$ In an observational study conducted among HCPs in a tertiary hospital in Ghana, a hand washing compliance rate ranging from $9.2 \%$ to $57 \%$ among doctors and $9.6 \%$ to $54 \%$ among nurses was reported. ${ }^{25}$ In the Egyptian study only $34 \%$ of the respondents had good practice of hand washing, ${ }^{21}$ In a similar study among HCPs in ICU in a tertiary hospital in Nigeria, hand washing compliance rate of $53 \%$ was reported. These figures are lower than the $69.5 \%$ of the respondents who had good hand washing practices in this study. Their exposure to training contributed to their good practices as evidenced by the statistically significant association found between HCPs who attended trainings/seminars on infection control and those who did not, with the former having a better hand washing practices (Fisher's exact $\mathrm{p}<0.001)$. It has also been documented that where attitude and habit are constant, behaviour is also constant and highly predictable. ${ }^{26}$ Thus, it can be inferred that a good knowledge and attitude towards hand washing may positively influence the practice of hand washing.

This study has also shown that HCPs tend to wash their hands more often after contact with patients then before contact and also after performing a bedside procedure than before such procedure. This finding is similar to that of other studies. ${ }^{22,27}$ In one of such studies, a hand washing rate of zero percent was reported before HCPs interacted with patients, this increased to $63 \%$ hand washing rate after HCPspatients interaction. ${ }^{27}$ This finding thus under-scores the need for urgent intervention measures by hospital management with respect to hand washing policy, emphasizing the need for hand washing before patients-HCPs contact/interaction. This observation is similar to the finding in other studies which reported that a major motivation to hand washing is fear of contracting disease from patients..$^{22}$ The patients are equally protected from infectious agents if all HCPs practice good hand hygiene.

As regards the variation in practice of hand washing, nurses were shown to have significantly better hand 
washing practices than the doctors (Fisher exact $p=$ 0.013). This finding is similar to a study conducted at Emergency Unit of Royal Infirmary in United Kingdom in which the nurses had a better hand washing practice than the doctors in all the observed patientHCPs interactions $\left(62.5 \%\right.$ and $20.7 \%$ respectively). ${ }^{28}$ However, it contrasts with the UPTH study in which doctors were found to have a better hand washing practice than the nurses. ${ }^{22} \mathrm{~A}$ possible explanation for the better hand washing practice among the nurses may be as a result of their longer contact/ interaction time with the patients especially on the wards while performing their nursing care. Also, some nursing procedures such as changing and emptying patient's urinary, diaper and beddings exposes them to highly infectious agents, and hence the need to wash their hands frequently is rather inevitable.

Many studies have shown that hand drying is as important as hand washing in maintaining a good hand hygiene..$^{29,30} \mathrm{~A}$ study conducted in Canada to assess the various hand drying techniques revealed that no matter what hand washing agents were used, a higher reduction of contamination was observed when using electric warm air hand dryer than using either disposable paper towel or cloth towel. Likewise, there was a higher reduction of contamination with the use of disposable paper towel than with the use of cloth towel. ${ }^{29,30}$ However, this study revealed that the hand drying technique among the respondents was poor. The use of personal handkerchief, natural air drying and common cloth towel were the commonly practiced hand drying techniques among the respondents. Perhaps if electric warm air hand dryers were available in the wards, they would have had better practices. This finding is similar to the UPTH study in which same hand drying techniques were observed..$^{22}$ The common cloth towel and handkerchief readily become damped and easily contaminated thus acting as a reservoir for infectious agents. ${ }^{27}$ The poor hand drying techniques observed in this study may invariably compromise the relatively good hand washing practices of the respondents, hence should be strongly discouraged. The use of common cloth towel has been reported in a study to be a barrier to good hand hygiene by HCPs. ${ }^{27}$ Unfortunately; this is the hand drying material available to the respondents in this institution.
Table IV. Hand hygiene practices of respondents

\begin{tabular}{lr} 
Practice $(\mathbf{n}=\mathbf{4 3 0})$ & Frequency $(\%)$ \\
\hline Wash hands before patient & \\
contact or bedside procedure & \\
Yes & $264(61.4)$ \\
No & $166(38.6)$ \\
\hline
\end{tabular}

\section{Wash hand after patient contact} or bedside procedure.

Yes

$416(97.7)$

No

$14(2.3)$

\section{Dry hands after washing}

Yes

$354(82.4)$

No

$76(17.6)$

\section{Washing of hands}

after the close of day's work

Yes

$331(77.0)$

No

$99(23.0)$

Hand washing

and drying methods

\section{Hand washing method used}

Use of running tap water only

$70(16.3)$

Use of running water +

294 (68.4)

antiseptic soap

$114(26.5)$

Use of alcohol hand rub only

$40(9.3)$

Use of soapy water in basin

7 (1.6)

Others

\section{Hand drying methods}

Use of common towel

$127(29.5)$

Allow hand to air dry

Use of disposable paper towel

$124(28.8)$

Use of personal handkerchief

Use of hand dryer

7 (1.6)

Others

\section{Multiple responses}

\section{Practice}

Good

$299(69.5)$

Fair

$124(28.8)$

Poor

7 (1.6) 


\section{Table V. Association between respondent's attendance at infection control training and their hand hygiene knowledge and practices}

\section{Attended training/seminar}

\begin{tabular}{lr} 
& Poor \\
\hline Yes & $1(0.4)$ \\
No & $4(2.1)$ \\
Total & $5(1.2)$
\end{tabular}

$\mathrm{X}^{2}=33.852 \mathrm{df}=4$; Fisher's exact $\mathrm{p}<0.001$

\begin{tabular}{rrrr} 
Poor & $\begin{array}{c}\text { Knowledge } \\
\text { Fair }\end{array}$ & Good & Total \\
\hline $1(0.4)$ & $24(9.9)$ & $218(89.7)$ & $293(100.0)$ \\
$4(2.1)$ & $44(23.5)$ & $139(74.3)$ & $187(100.0)$ \\
$5(1.2)$ & $68(15.8)$ & $357(83.0)$ & $430(100.0)$
\end{tabular}

\section{Attended training/seminar}

\begin{tabular}{lrrrr} 
& Poor & Fair & Good & Total \\
\hline Yes & $0(0.0)$ & $52(21.4)$ & $191(78.6)$ & $243(100.0)$ \\
No & $7(3.7)$ & $72(38.5)$ & $108(57.8)$ & $187(100.0)$ \\
Total & $7(1.6)$ & $124(28.8)$ & $229(69.5)$ & $430(100.0)$ \\
\hline
\end{tabular}

$X^{2}=141.059 ; \mathrm{df}=4$; Fisher's exact $\mathrm{p}<0.001$

A major motivation to hand washing in this study was the fear of contracting disease as $47 \%$ of the respondents agree with his assertion. This finding has also been reported by other authors. ${ }^{22,31,32}$ Similar to findings from other studies, ${ }^{33,34}$ our respondents strongly alluded to the fact that busy work schedule may hinder their hand washing compliance. This reason may not be far-fetched, considering the fact that there is dearth of medical personnel in our environment and the available ones are often overworked often leaving them with little or no time in between patient care for proper hand washing. Although, more than half $(54.9 \%)$ of the respondents strongly agreed that hand washing may be improved by administrative order, but such an order without the necessary hand washing facilities especially the hand drying materials (single use disposable paper towel or warm air electric hand dryer) identified in this study, may be an order in futility. In a multicentre survey to determine measures that may help HCPs to improve on their hand hygiene, most respondents in the survey were not in favour of interventions involving rewards or punishment but were more attracted to interventions that make hand washing easier such as provision and easy accessibility to hand washing materials and continuous health education on infection control and hand washing. ${ }^{35}$ These measures if put in place will greatly enhance hand washing practices among HCPs.

Table VI. Association between respondent's profession and hand washing practices

\begin{tabular}{|c|c|c|c|c|}
\hline \multirow[t]{2}{*}{ Profession } & \multicolumn{2}{|c|}{$\begin{array}{c}\text { Hand washing before contact/ } \\
\text { bedside procedure }(\%)\end{array}$} & \multicolumn{2}{|c|}{$\begin{array}{c}\text { Hand washing after } \\
\text { contact/bedside procedure (\%) }\end{array}$} \\
\hline & Yes & No & Yes & No \\
\hline Doctors & $108(47.5)$ & $122(53.0)$ & 227 (98.7) & $3(1.3)$ \\
\hline \multirow[t]{2}{*}{ Nurses } & $156(78.0)$ & $44(22.0)$ & $189(94.5)$ & $11(5.5)$ \\
\hline & \multicolumn{2}{|c|}{$\mathrm{x} 2=43.497, \mathrm{p}<0.001$} & \multicolumn{2}{|c|}{$x 2=5.979, p=0.014$} \\
\hline \multicolumn{5}{|c|}{ Practice } \\
\hline & Poor & Fair & \multicolumn{2}{|l|}{ Good } \\
\hline Doctors & $2(0.9)$ & $79(34.3)$ & \multicolumn{2}{|l|}{149 (64.8) } \\
\hline Nurses & $5(2.5)$ & $45(22.5)$ & \multicolumn{2}{|l|}{$150(75.0)$} \\
\hline Total & $7(1.6)$ & $124(28.8)$ & \multicolumn{2}{|l|}{299 (69.5) } \\
\hline
\end{tabular}

$\underline{X^{2}=8.560 ;} \mathrm{df}=2 ;$ Fisher exact $\mathrm{p}=0.013$ 


\section{Conclusion}

HCPs in LUTH have good knowledge and attitude to hand washing. Hand washing was higher after patient contact than before. Hand-drying practices were poor and this may invariably jeopardize the relatively good hand washing practices. Busy work schedule in between patient care was identified as a possible constraint to hand washing. We recommend emphasis on the importance of hand washing before contact with patients and improvement in HCP to patient ratio. Electric warm air hand dryers and single use disposable paper towels should be provided in the wards.

\section{References}

1. Pittet D, Hugonnet $S$, Harbarth $S$, et al. Effectiveness of a hospital-wide programme to improve compliance with hand hygiene. Infection control Programme. Lancet 2000; 356: 1307-1312. http://dx.doi.org/10.1016/S0140-6736(00)028142

2. Albert RK, Condie F. Hand washing pattern in medical intensive care units. N Engld Med 1981; 304: 1465-1466. http://dx.doi.org/10.1056/NEJM198106113042404

3. Pittet D, Mourouga P, Pemeger TV. Compliance with hand washing in a teaching hospital infection control programme. Ann Intern Med 1999; 130: 126-130. http://dx.doi. org/10.7326/0003-4819-130-2-199901190-00006

4. World Health Organization (WHO). Practical guidelines for infection control in health care facilities. Geneva, WHO 2004; Annex 1: 76-80.

5. Pittet D, Allegranzi B, Storr J, Donaldson L. 'Clean Care is Safer Care': The Global patient safety challenges 2005-2006. Int I Infect Dis 2006; 10(6): 419-424. http://dx.doi.org/10.1016/j. ijid.2006.06.001

6. Vincent JL. Nosocomial infections in adult intensive care unit. Lancet 2003; 361: 2068-2077. http://dx.doi.org/10.1016/ S0140-6736(03)13644-6

7. Vincent JL, Bihari DJ, Suter PM, et al. Prevalence of nosocomial infection in ICU in Europe. Result of the European prevalence of infection in ICU (EPIC) study. EPIC international advisory committee. JAMA 1995; 274: 639-644. http://dx.doi. org/10.1001/jama.1995.03530080055041

8. Pittet D, Allegranzi B, Sax $H$, et al. Consideration for a WHO- European strategy on healthcare associated infection, surveillance and control. Lancet Infect Dis 2005; 5(4): 242250. http://dx.doi.org/10.1016/S1473-3099(05)70055-4

9. Pittet D, Tarara D, Wenzel RP. Nosocomial blood stream infection in critically ill patient. Excess length of stay, extra cost and attributable mortality. JAMA 1994; 271(20): 15981601. http://dx.doi.org/10.1001/jama.1994.03510440058033

10. Klevens R, Edward JR, Richards CL Jr, et al. Estimating healthcare associated infections and deaths in US hospitals, 2002. Public Health Report 2007; 122(2): 160-166.

11. Stone PN, Braccia D, Larsson E. Systematic review of economic analyses of healthcare associated infections. Am Journal of Infection Control 2005; 33: 501-509. http://dx.doi. org/10.1016/j.ajic.2005.04.246

12. Allengranzi B, Pittet D. Healthcare associated infection in developing countries: Simple solution to meet complex challenges. Infect Control Hosp Epidemiol 2007; 28(12): 1323- 1327. http://dx.doi.org/10.1086/521656
13. Pittet D, Allegranzi B, Storr J, et al. Infection control as a major WHO priority for developing countries. I Hosp Infect 2008; 68(4): 285-295. http://dx.doi.org/10.1016/j.jhin.2007.12.013

14. Dumpis U, Balode A, Vigante D, et al. Prevalence of nosocomial infection in two Latvian hospital. Euro-surveill 2003; 8(3): 73-78.

15. Azzam R, Dramaix MA. A one day prevalence survey of hospital acquired infections in Lebanon. I Hosp Infect 2001; 49: 74-78. http://dx.doi.org/10.1053/jhin.2001.1043

16. Gosling R, Mbatia R, Savage A, Mulligan JA, Reyburn $H$. Prevalence of hospital acquired infections in a tertiary referral hospital in northern Tanzania. Ann Trop Med Parasitol 2003; 97(1): 69-73. http://dx.doi. org/10.1179/000349803125002724

17. Won SP, Chou HC, Hsieh WS. Hand washing programme for the prevention of nosocomial infections in a neonatal intensive unit. Infect Control Hosp Epidemiol 2004; 25(9): 742-746. http://dx.doi.org/10.1086/502470

18. Creedon SA. Healthcare workers' hand decontamination practices: compliance with recommended guidelines. J Adv Nur 2005; 51(3): 208-216. http://dx.doi.org/10.1111/j.13652648.2005.03490.x

19. Christaens CR, Barbier C, Musters J, Warnotte J. Hand hygiene: First measure to control nosocomial infection. Rev Med Liege 2006; 61(1): 31-36.

20. Raman S, Meenakshi S, Vipin K. Hand washing compliance among healthcare staff in intensive care unit of a Multispecialty hospital of north India. J Hosp Administration 2012; 1(2): 2733.

21. Abd Elaziz KM, Bakr IM. Assessment of knowledge attitude and practice of hand-washing among healthcare workers in Ain Shams University Hospital Cairo. The Egyptian Journal of Community Medicine 2008; 26: 50-54.

22. Balafama A, Opara P. Hand-washing practices amongst health workers in a teaching hospital. Am / Infect Dis 2011; 7(1): 8-15. http://dx.doi.org/10.3844/ajidsp.2011.8.15

23. Nobile C, Diac E, Mantuori P, Villari P. Healthcare personnel and hand washing. Decontamination in intensive care units: knowledge, attitude and behavior in Italy. I Hosp Infect 2002; 51(3): 226-232. http://dx.doi.org/10.1053/jhin.2002.1248

24. Tobi KU, Enyi-Nwafor K. Hand washing practices and compliance among healthcare workers in intensive care unit of a tertiary hospital in Nigeria. Nigerian Medical Practitioner 2013; 63(4).

25. Alfred $\mathrm{EY}, \mathrm{Afua} \mathrm{AJH}$. Hand hygiene practices and resources in a teaching hospital in Ghana. J Infect Dev Ctries 2013; 7(4): 338-347.

26. Gbolahan G. Attitude, value and behavior. In: Moruf A, Gbolahan G, Eds. Organizational Behaviour: A Basic Introduction, $2^{\text {nd }}$ edn. Lagos State, Shomolu, Pumark Publishers Nig Ltd. 2009; 87-99.

27. Thompson BL, Dwyer DM, Ussery XT. Hand washing and gloves use in a long-term care facility. Infect Control Hosp Epidemiol 1997; (18): 97-103. http://dx.doi.org/10.1086/647562

28. Rumgay S, Macdonald S, Robertson CE. Hand washing pattern and infection control in the accident/emergency department. Arch Emerg Med 1984; 1(3): 157-159. http://dx.doi. org/10.1136/emj.1.3.157

29. Gustafson DR, Vetter EA, Larson DR, et al. Effect of four handdrying methods for removing bacterial from washed hands: a randomized trial. Mayo Clin Proc 2000; 75(7): 705-708.

30. Ansari SA, SpringthorpeVS, Satter SA, Tostowaryk W, Wells GA. Comparison of cloth, paper and warm air drying in eliminating viruses and bacteria from washed hands. Am I Infect Control 1991; 19(5): 243-249. http://dx.doi.org/10.1016/S01966553(05)80256-1 
31. Gould D. Infection control. Making sense of hand hygiene. Nurs Times 1994; 90: 63-64.

32. Tibbals J. Teaching hospital medical staff to hand wash. Med J Aust 1996; 164(7): 395-398.

33. Sproat LJ, Inglis TJ. Multicentre survey of hand hygiene practices in intensive care units. J Hosp Infect 1994; 26(2): 137-148. http://dx.doi.org/10.1016/0195-6701(94)90057-4

34. Larson E, Killien M. Factors influencing hand washing behavior of patient care personnel. Am J Infect control 1982; 10(3): 9399. http://dx.doi.org/10.1016/0196-6553(82)90019-0

35. Harris AD, Samore MH, Nafziger R, DiRosario K, Roghmann MC, Carmeli Y. A survey on handwashing practices and opinions of healthcare workers. J Hosp Infect 2000; 45(4): 318-321. http://dx.doi.org/10.1053/jhin.2000.0781 